\section{A call to action: Temporal trends of COVID-19 deaths in the South African Muslim community}

To the Editor: The correspondence by Waasila Jassat et al..$^{[1]}$ warrants a few comments in terms of satisfying scientific scrutiny. The authors erroneously assert that compared with whites, South Africans of lndian origin have a 35\% increased risk of dying of COVID-19 when hospitalised, and that the mortality rate is $11 \%$ higher than that for black South Africans. Yet perusal of their reference $1^{[2]}$ does not support their contention. Scrutiny of the figure on p. 13 of the reference, giving the odds ratio (OR) for inhospital mortality, shows that the OR for Indians and black Africans is the same, viz. 1:3. In other words, both black Africans and Indians show a $30 \%$ higher in-hospital mortality rate compared with whites. The OR for coloureds was 1:2. ${ }^{[2]}$ This observation corroborates a previous report by the same group (National Institute for Communicable Diseases) that found a higher mortality from COVID-19 in black Africans and coloureds compared with whites. ${ }^{[3]}$ Another point that needs clarification in Jassat $e t$ al.'s letter ${ }^{[1]}$ relates to their graph on excess natural deaths compared with Muslim COVID-19 deaths (Fig. 2B). The value of this statistic is questionable when cognisance is taken of the fact that the trajectory of the total number of COVID-19 deaths has been omitted.

The data for COVID-19-related mortality are based on statistics provided by a group called Muslim Stats South Africa. It would be interesting to know the precise methodology used in gathering its information from the various 'Muslim community organisations', which presumably consist of Muslim burial societies.

While I concur with the sentiments relating to the importance of taking appropriate preventive measures against this dreaded disease, I do feel that published data should be accurate, reliable and in accordance with sound scientific principles.

\section{A K Omar}

Department of Diabetes and Endocrinology, Nelson Mandela School of Medicine, College of Health Sciences, University of KwaZulu-Natal, Durban, South Africa

momars@telkomsa.net

1. Jassat W, Brey Z, Parker S, Wadee M, Wadee S, Madhi SA. A call to action: Temporal trends of COVID-19 deaths in the South African Muslim community. S Afr Med J 2021;111(8):692-694. https:// doi.org/10.7196/SAMJ.2021.v111i8.15878

2. National Institute for Communicable Diseases. COVID-19 hospital surveillance update. South Africa, Week 14 2021. Johannesburg: NICD, 2021. https://www.nicd.ac.za/wp-content/uploads/2021/04/ NICD-COVID-19-Weekly-Hospital-Surveillance-update-Week-14-2021.pdf (accessed 29 June 2021).

3. South African Government News Agency. Black Africans, Coloureds and males likely to die of COVID-19. 20 August 2020. https://www.sanews.gov.za/south-africa/black-africans-coloureds-andmales-likely-die-covid-19 (accessed 29 June 2021).

Jassat et al. respond: We provide the following clarification on the issues raised.

The higher mortality risk among individuals of Indian ancestry following COVID-19 hospitalisation was described. The cited reference $^{[1]}$ was inadvertently not updated with the more recent analysis, ${ }^{[2]}$ which included 219265 hospitalised COVID-19 cases, undertaking multiple chained imputation to account for missing data, increasing the power of the analysis. The mortality risk following COVID-19 hospitalisation in people of Indian ancestry was $11 \%$ higher than in other race groups (unpublished) and 35\% higher than in whites. ${ }^{[2]}$
Excess mortality, the trajectory that is highly synchronous with documented COVID-19 deaths in South Africa (SA), ${ }^{[3]}$ as a proxy of actual number of COVID-19 deaths was used to quantify the burden of COVID-19 deaths in SA more accurately. The high degree of synchrony between recorded COVID-19 deaths and excess mortality suggests that the majority of deaths imputed from excess mortality are likely to be due to COVID-19. In our analysis, we plotted the temporal association of reported COVID-19 deaths from Muslim Stats South Africa in relation to both the recorded and excess mortality data from Gauteng Province. Both these analyses support that the surge of reported COVID-19 deaths in the Muslim community in Gauteng preceded deaths in the general population.

Finally, Muslim Stats South Africa obtains data from a network of Muslim burial societies and community organisations certified to undertake burial of people who have died of COVID-19 across the country. The organisation reports daily stats from the reporting undertakers, which include age, sex and location of death as recorded on the Department of Home Affairs DHA-1663 death notification form. These are deaths confirmed to be due to COVID-19, and may actually under-estimate the burden of COVID-19 deaths in the community owing to under-reporting or absence of investigation for COVID-19 in the decedents.

\section{Waasila Jassat}

Division of Public Health Surveillance and Response, National Institute for Communicable Diseases of the National Health Laboratory Service, Johannesburg, South Africa waasilaj@nicd.ac.za

\section{Zameer Brey}

Bill and Melinda Gates Foundation, South Africa Office, Cape Town, South Africa

\section{Salim Parker}

Division of Infectious Diseases and HIV Medicine, Faculty of Health Sciences, University of Cape Town, South Africa

\section{Muhammad Wadee}

Muslim Stats South Africa, Johannesburg, South Africa

\section{Shoyab Wadee}

Wits Donald Gordon Medical Centre, Johannesburg, South Africa; and Islamic Medical Association, Johannesburg, South Africa

\section{Shabir A Madhi}

South African Medical Research Council, Vaccines and Infectious Diseases Analytics Research Unit, School of Pathology, Faculty of Health Sciences, University of the Witwatersrand, Johannesburg, South Africa

1. COVID-19 hospital surveillance update. South Africa, Week 14 2021. Johannesburg: NICD, 2021. https://www.nicd.ac.za/wp-content/uploads/2021/04/NICD-COVID-19-Weekly-HospitalSurveillnace-update-Week-14-2021.pdf (accessed 10 June 2021).

2. Jassat W, Cohen C, Tempia S, et al. A national cohort study of COVID-19 in-hospital mortality in South Africa: The intersection of communicable and non-communicable chronic diseases in a high HIV prevalence setting. medRxiv 2021 (epub 4 July 2021). https://doi.org/10.1101/2020.12.21.20248409

Moultrie T, Dorrington R, Laubscher R, Groenewald P, Bradshaw D. Correlation of excess natural deaths with other measures of the COVID-19 pandemic in South Africa. Burden of Disease Research Unit, South African Medical Research Council, 23 February 2021. https://www.samrc.ac.za/sites/ default/files/files/2021-03-03/CorrelationExcessDeaths.pdf (accessed 10 June 2021).

S Afr Med J 2021;111(9):818. https://doi.org/10.7196/SAMJ.2021.v111i9.15929 